\title{
CONTROLE DE CLADOSPORIUM FULVUM EM TOMATEIRO POR EXTRATOS DE PLANTAS MEDICINAIS
}

\section{A.T. Itako ${ }^{1}$, K.R.F. Schwan-Estrada ${ }^{1}$, J.R. Stangarlin' ${ }^{2}$, J.B. Tolentino Júnior ${ }^{1}$, M.E.S. Cruz ${ }^{1}$}

1Universidade Estadual de Maringá, Departamento de Agronomia, Av. Colombo, 5790, CEP 87020-900, Maringá, PR, Brasil. E-mail: atitako@yahoo.com.br

\section{RESUMO}

\begin{abstract}
Atualmente, tem-se estudado a utilização de extratos de plantas medicinais no controle de fitopatógenos. Assim, este trabalho objetivou avaliar a fungitoxidadeinvitrodos extratos brutos aquosos (EBAs) de Achillea millefolium, Artemisia camphorata, Cymbopogon citratus e Rosmarinus officinalis contra Cladosporium fulvume o efeito protetor destes extratos para a cladosporiose em plantas de tomateiro em casa-de-vegetação. Para avaliar a atividade antifúngica, os EBAs foram incorporados ao meio de cultura BDA (batata-dextrose e ágar) e avaliada a inibição do crescimento micelial, a esporulação e a germinação de esporos. O efeito protetor em plantas foi verificado através da pulverização preventiva dos EBAs, $72 \mathrm{~h}$ antes da inoculação, nas concentrações de $10 \%$ e $20 \%$, no primeiro par de folhas. A severidade da doença foi verificada 20 dias

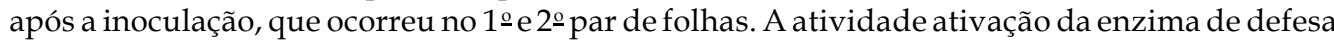
peroxidase foi avaliada por método espectrofotométrico direto em folhas coletadas $72 \mathrm{~h}$ após a inoculação. Verificou-se que os EBAs inibiram o crescimento micelial e tiveram efeitos significativos na redução da esporulação e da germinação de esporos, principalmente os EBAs de $A$. camphorata e $R$. officinalis, que nas concentrações de $20 \%$ e $40 \%$ reduziram $85,72 \%$ e $93,49 \%$ a esporulação, respectivamente. Verificou-se, in vivo, uma redução no número de lesões e uma possível indução resistência dos EBAs, principalmente para A. camphorata e $R$. officinalis. A atividade de peroxidase não teve incrementos significativos em relação à testemunha, no tempo analisado.
\end{abstract}

PALAVRAS-CHAVE: Indução de resistência, peroxidase, controle alternativo.

\begin{abstract}
CONTROL OF CLADOSPORIUM FULVUM IN TOMATO PLANTS BY EXTRACTS OF MEDICINAL PLANTS. THERE HAVE BEEN VARIOUS RECENTSTUDIES CONCERNING THE USEOF medicinal extracts of medicinal plants for the control of phytopathogens. The present study was therefore aimed to evaluate, in vitro, fungitoxicity of aqueous crude extracts (ACEs) of Achillea millefolium, Artemisia camphorata, Cymbopogon citratus and Rosmarinus officinalis against Cladosporium fulvum, and the protective effect of these extracts in tomato plants under greenhouse conditions. To evaluate antifungical activity, ACEs were incorporated to PDA (potato-dextrose-agar), with observation of inhibition of mycelial growth, sporulation and spores germination. The plant protection was verified by preventive spraying 72 hours before inoculation of ACEs, in $10 \%$ and $20 \%$ concentration, in the first pair of leaves. The severity was evaluated 20 days after inoculation, which occurred in both the first and second pair of leaves. Theactivity of the plant-defense enzyme peroxidase was evaluated spectrophotometrically in leaves 72 hours after treatments. It was verified that ACEs inhibit the mycelial growth and had significant reduction in sporulation and spore germination, mainly by ACEs of A. camphorata and R. officinalis, in concentration of $20 \%$ and $40 \%$, which reduced the sporulation $85.72 \%$ and $93.49 \%$, respectively. In relation to the in-vivo treatments there was observed a reduction in the number of lesions along with a possible resistance induction, mainly to A. camphorata and R. officinalis extracts. The peroxidase activity had no significant increment in relation to the control treatment.
\end{abstract}

KEY WORDS: Resistance induction, peroxidase, alternative control.

\footnotetext{
${ }^{2}$ Universidade Estadual do Oeste do Paraná, Marechal Cândido Rondon, PR, Brasil.
} 


\section{INTRODUÇÃO}

O tomateiro tem seu cultivo amplamente difundido em nosso país, e apresenta grande importância comercial, tanto para o consumo innatura quanto para industrialização (FIlgueIra, 2003; AlvarengA, 2004). É a segunda olerícola mais cultivada em nível mundial, apenas superada pela cultura da batata (FILGUeIRA, 2003). O cultivo do tomateiroexigealtonível tecnológicoeintensa utilização de mão-de-obra, o que confere a esta cultura elevada importância econômica e social (LopEz et al., 2000), além deseruma cultura ondemais de 100 doenças já foram relatadas, provocando diferentes níveis de redução de produtividade ou de qualidade do produto comercial. Dentre as doenças fúngicas que podem causar perdassignificativasnacultura estáa cladosporiose, causada por Cladosporium fulvum.

A utilização defungicidas químicos sintéticos tem alcançado sucesso no controle de várias doenças. No entanto, seu usoindiscriminado tem contribuído para a seleção de patógenos resistentes aos fungicidas e causado poluição ambiental, gerando risco à saúde humana e animal (PRITHIVIRAj et al., 1997; STADNIK; Talamini, 2004; AgÊNCIA Nacional de VigilânCia SANITÁRIA, 2005). Outras opções para o controle de doenças estão disponíveis, tais como o uso de cultivares resistentes, controle biológico, rotação decultura e o uso de métodos alternativos (STANGARLIN et al., 1999; Cavalcanti et al., 2005).

Novos produtos estão surgindo no mercado, compostos de moléculas com a capacidade de ativação de diferentes mecanismos de defesa na planta, a chamada resistência induzida, criando um sistema multicomponente com amplo espectro de ação contra patógenos (KeSSMAN et al., 1994; CAVAlCANTI et al., 2005). Essa resistência induzida é iniciada quando um agente indutor sinaliza a planta para ativar a produção de componentes de defesa. Uma das vantagens de se estimular a resistência induzida é que a planta, uma vez imunizada, tem seus mecanismos de defesa ativados por um longo período de tempo, geralmente até o florescimento, limitando, desta forma, o número de aplicações necessárias para o controle efetivo da doença (LYON et al., 1995).

Os mecanismos de resistência induzidos podem ser estruturais, como lignificação e formação de papilas, ou respostas bioquímicas, como acúmulo de fitoalexinas e de proteínas relacionadas com a patogênese, tais como $\beta$-1,3-glucanases e quitinases, degradadoras da parede celular dos fungos (Pascholati; Leite, 1995). Outros mecanismos ativos de defesa das plantas contra fitopatógenos envolvem alterações metabólicas correlacionadas com mudanças na atividade de enzimas chaves nos metabolismos primários e secundários como, por exemplo, nas enzimas peroxidase e fenilalanina amônia-liase.
Dadaà riqueza química das plantas medicinais, que possuem princípios ativos microbiocidas, estas se tornam fontes potenciais de moléculas que poderiam ser empregadas na defesa de plantas contra fitopatógenos, tantopelaatividadeantimicrobianaquanto pelaindução deresistência (ScHWAN-ESTRADA;STANGARLIN, 2005). Como exemplos, têm-se o extrato de cúrcuma (Curcuma longa) que apresentou fungitoxicidade in vitro através da inibição do crescimento micelial de Fusarium udum (Berk.) Wollenw (SINGH, RAI, 2000) e redução no crescimento micelial e a germinação in vitro de escleródios de Macrophomina phaseolina (Tassi) Goid (RAJA;KuRUCHEVE, 1998). Outros exemplos são o controle da requeima (Phytophthora infestans) em batata pelo extrato de cavalinha (Equisetum sp.)(Ke-QIANG; BRUGGEN, 2001), do oídio(Oidium lycopersici)em tomateiroporextratoseóleo de nim (Azadirachta indica) (CARNEIRO, 2003) e da pinta preta (Alternaria solani) em tomateiro por extrato de cúrcuma e curcumina (BALBFPEÑa et al., 2006a; 2006b).

$\mathrm{Na}$ busca de novas fontes de eliciadores de resistência contra fitopatógenos, as plantas medicinais Achillea millefolium (mil-folhas), Artemisia camphorata (cânfora), Cymbopogon citratus (capim-limão) e Rosmarinus officinalis (alecrim) têm demonstrado potencial no controle de fitopatógenos (BECKERet al.2004; FRANZENER et al., 2003).

Assim, o objetivo do trabalho foi avaliar o EBA destas quatro plantas medicinais na inibição do crescimento micelial, esporulaçãoe germinação deesporos in vitro de Cladosporium fulvum e o efeito protetor destes extratos em plantas de tomateiro contra a cladosporiose, em casa-de-vegetação.

\section{MATERIAL E MÉTODOS}

Crescimento micelial, esporulação e germinação de esporos de Cladosporium fulvum

O experimento foi realizado no laboratório de Fitopatologia da Universidade Estadual de Maringá. Folhas frescas das plantas medicinais $A$. millefolium, $A$. camphorata, C. citratus e R. officinalis foram trituradasem caldo de batata por $3 \mathrm{~min}$, em liquidificador. Os homogenatos resultantes foram filtrados em gaze e em papeldefiltroWhatman $\mathrm{n}$-1, obtendo-seoextrato bruto aquoso (EBA), o qual foi incorporado ao BDA (batatadextrose-ágar, esterilizado por autoclavagem) nas concentrações de 1\%, 10\%, 20\% e 40\% e distribuído em placas de Petri. Após a solidificação do meio, um disco com $8 \mathrm{~mm}$ de diâmetro de micélio do isolado, com 10 dias de idade em BDA, foi repicado para o centro das placas, as quais foram vedadas com filme plástico e mantidas a $28^{\circ} \mathrm{C} \pm 2^{\circ} \mathrm{C}$ e escuro. A avaliação foi realizada através da medição diária do diâmetro das colônias (média de duas medidas diametralmente 
opostas), iniciando 24 h após a instalação do experimento eperdurandoaté o momento em queas colônias fúngicas no tratamento controle cobrissem $2 / 3$ da superfície do meio decultura. Nessemomento, também realizou-se a contagem de esporos. Para isso, foram adicionados $10 \mathrm{~mL}$ de água destilada em cada placa, e a suspensão foi filtrada em gaze. A contagem foi realizada em câmara de Neubauer em microscópio óptico. A influência dos extratos das plantas sobre a germinação de esporos foi determinada através do uso de placas utilizadas em teste de ELISA. Cada poçinho da placa recebeu alíquota de $80 \mu \mathrm{L}$ da suspensão de esporos $\left(10^{4}\right.$ esporos $\left.\mathrm{mL}^{-1}\right)$ e foram incubadas em câmara úmida, sob luz constante, à temperatura de $24^{\circ} \mathrm{C}$. A porcentagem de germinação de esporos foi avaliada $12 \mathrm{~h}$ após oinício do experimento, com basena contagem de 100 esporos por repetição. A germinação foi paralisada com uma gota de corante azul de algodão com lactofenol, e a contagem foi efetuada ao microscópio óptico. A avaliação foi realizada pela contagem de esporos germinados sendo considerados germinados quando apresentaram qualquer emissão de tubo germinativo. Utilizou-se o delineamento experimental inteiramente casualizado (DIC) com 17 tratamentos e 4 repetições, em esquema fatorial $4 \times 4+1$, cujos fatores foram 4 EBAs, 4 concentrações $(1 \%, 10 \%, 20 \%$ e $40 \%)$ e testemunha. Os dados obtidos foram submetidos à análise de variância $(p=0,05)$ e quando significativos foram analisados por regressão.

\section{Avaliação da severidade da doença em plântulas de tomate}

Sementes de tomate cv. Santa Clara foram semeadas embandejas deisoporde128célulascontendosubstrato comercial. As mudas foram transplantadas aos 21 dias após semeadura para vasos de 2 L contendo uma mistura autoclavada de solo e areia (1:1). Para determinar a ativação de mecanismos de resistência nas plântulas, $\mathrm{O}$ primeiro par defolhas verdadeiras recebeu EBA decada uma das plantas nas concentrações de $10 \%$ e $20 \%$, por aspersão até o ponto de escorrimento. A testemunha recebeu somente água. Setenta e duas horas após a aplicação dos tratamentos, o primeiro par de folhas (1 1 a e2 a folha) e o segundo par de folhas (3a e 4a folha) nãotratadasforaminoculad oscom suspensão de $10^{4}$ esporos $\mathrm{mL}^{-1}$ do fungo C. fulvum. Após a inoculação, as plantas forammantidasem sala deincubaçãoa $25^{\circ} \mathrm{Cecondição}$ dealta umidaderelativa, obtida com câmaraúmida, por 24h, sendo, em seguida, transferidas para casa-de-vegetação. A avaliação da severidade da doença foi realizada 20 dias após a inoculação, anotando-se o número de lesões nas folhas tratadas enão-tratadas. Odelineamentoexperimentalusadofoi inteiramentecasualizadocom três repetições, sendo cada parcela composta por duas plantas. Os dados obtidos foram analisados estatistica- mente pela análise de variância, aplicando-se o teste de Scott-Knotta 5\% de probabilidade para comparação das médias.

\section{Determinação da atividade da enzima peroxidase}

Para análise da enzima peroxidase, $72 \mathrm{~h}$ após a inoculação foram coletadas as folhas tratadas. Estas foram pesadas e homogeneizadas separadamente em almofariz de porcelana com $4 \mathrm{~mL}$ de tampão fosfato 0,1 $\mathrm{M}(\mathrm{pH} 6,0)$ a $4^{\circ} \mathrm{C}$. O homogeneizado foi centrifugado a $20.000 \mathrm{~g}$ por $10 \mathrm{~min}$ e recolhido o sobrenadante. Em cubeta de vidro com capacidade de $3 \mathrm{~mL}$, foramadicionados 2,9 mL de tampão de reação $\left(153 \mu \mathrm{L}\right.$ de $\mathrm{H}_{2} \mathrm{O}_{2}+$ $6,25 \mathrm{~mL}$ de guaiacol (2\%) em $50 \mathrm{~mL}$ de tampão de extração) e 0,1 mL do sobrenadante. A reação foi seguida espectrofotometricamente pela alteração na absorção a $470 \mathrm{~nm}$, durante $4 \mathrm{~min}$ (HAMMERSCHMIDT et al., 1982). A quantificação de proteínas totais presentes no extrato enzimático foi determinada utilizando-se o método de BRADFORD (1976). A cada 0,8 mL de amostra foi adicionado, sob agitação, $0,2 \mathrm{~mL}$ de reagente concentrado de Bradford. Após 5 min de incubação à temperatura ambiente, realizou-se a leitura de absorbânciaa595nm. Comoreferência foi utilizado 0,8 mLdeágua destilada e $0,2 \mathrm{~mL}$ dereagenteconcentrado de Bradford. A concentração de proteínas de cada amostra, expressa em termos de equivalentes $\mu \mathrm{g}$ de albumina de soro bovino (ASB) em $0,8 \mathrm{~mL}$ de amostra ( $\mu$ g proteína/0,8 $\mathrm{mL}$ ), foi determinada utilizando-se curva padrão de concentrações de ASB variando de 0 a $20 \mu \mathrm{g} / 0,8 \mathrm{~mL}$. A atividade específica da enzima foi expressa em $\Delta \mathrm{Abs}_{470} \mathrm{~nm} / \mathrm{min} / \mathrm{g}$ proteína. Os dados de atividade específica da enzima peroxidase foram analisados estatisticamente pela análise de variância, aplicando-se o teste de Scott-Knott a 5\% de probabilidade para comparação das médias.

\section{RESULTADOS E DISCUSSÕES}

\section{Atividade antifúngica}

No crescimento micelial (Fig. 1) para o EBA de $A$. millefolium, a equação ajustada foi quadrática, onde a maior inibição foi na concentração de 34,79\% com redução de $21,83 \%$ docrescimento micelial.Para oEBA de A. camphorata, a maior inibição ocorreu na concentração de $31,09 \%$, inibindo $53,42 \%$ do crescimento. Já para a planta C. citratus a maior inibição foi em $40,67 \%$ do EBA, inibindo 20,03\% do crescimento micelial em relação à testemunha. Para o EBA de $R$. officinalis os dados se ajustaram a uma reta, onde com o aumento da concentração do EBA houve redução do crescimento micelial. Na concentração de $40 \%$ ocrescimento micelial foi reduzido 49,06\% em relação à testemunha. 


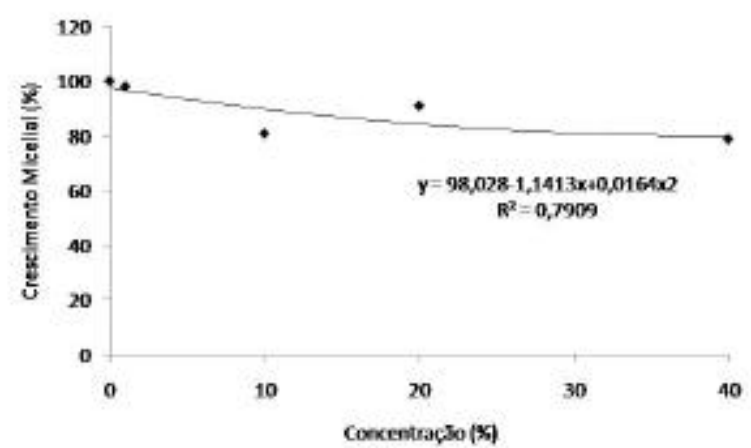

(a)

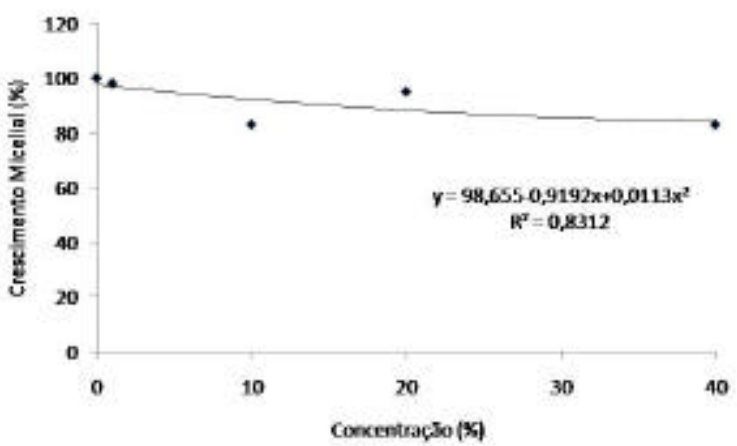

(c)

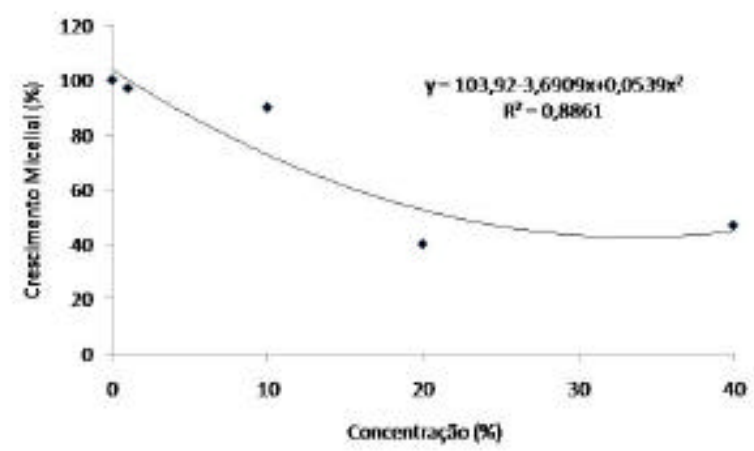

(b)

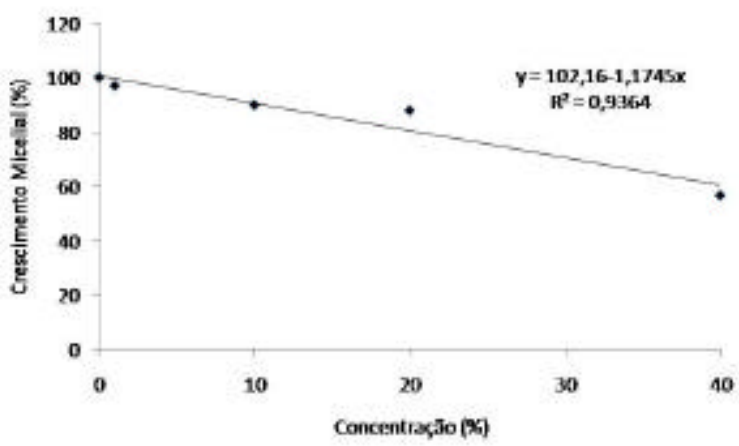

(d)

Fig. 1 - Porcentagem de crescimento micelial de Cladosporium fulvum sob diferentes concentrações de extratos brutos aquosos de (a) Achillea millefolium (b) Artemisia camphorata (c) Cymbopogon citratus e (d) Rosmarinus officinalis. Para a concentração $0 \%$ foi considerada um crescimento micelial de $100 \%$.

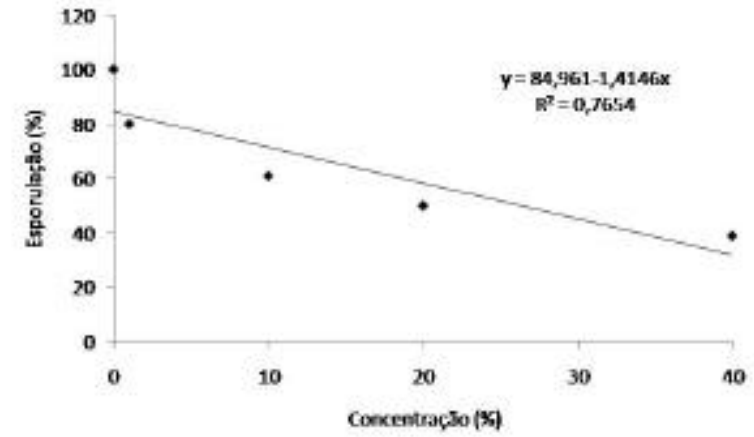

(a)

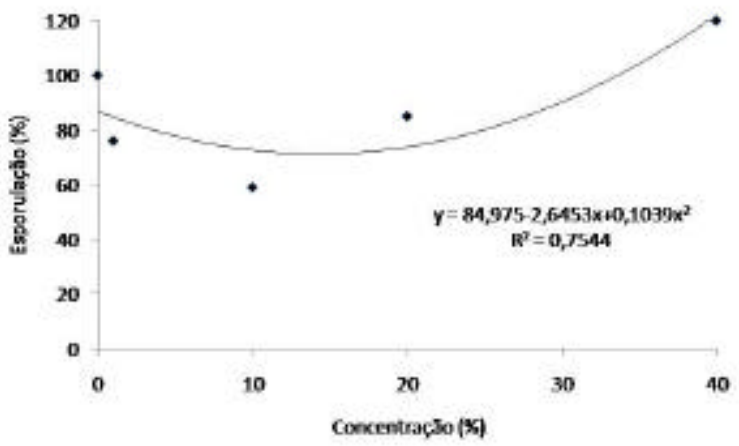

(c)

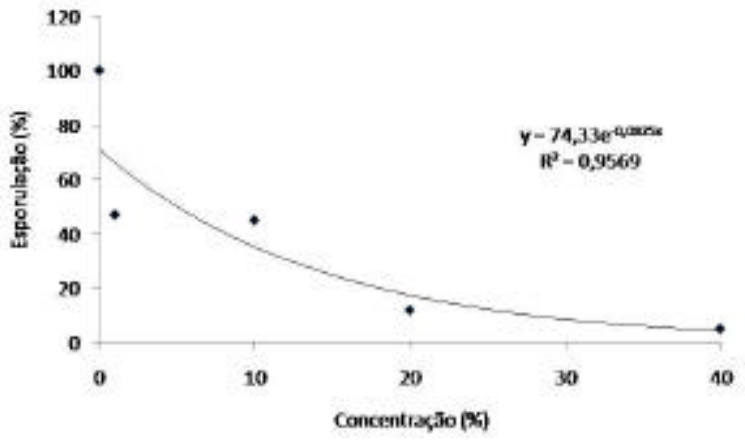

(b)

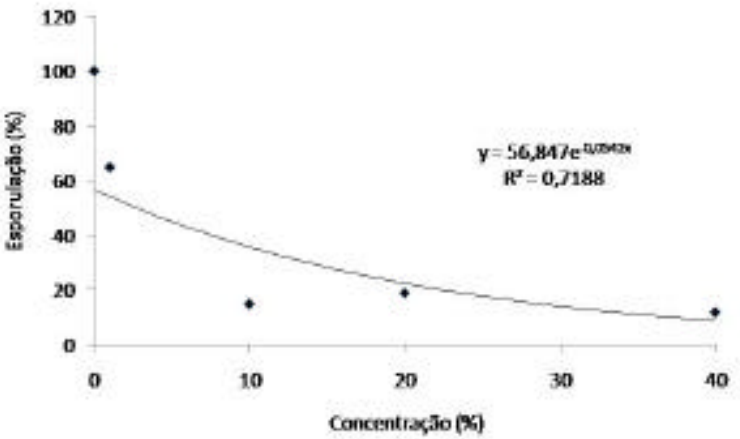

(d)

Fig. 2 - Porcentagem de esporulação de Cladosporium fulvum sob diferentes concentrações de extratos brutos aquosos de (a) Achillea millefolium (b) Artemisia camphorata (c) Cymbopogon citratus e (d) Rosmarinus officinalis. Para a concentração $0 \%$ foi considerada uma esporulação de $100 \%$. 


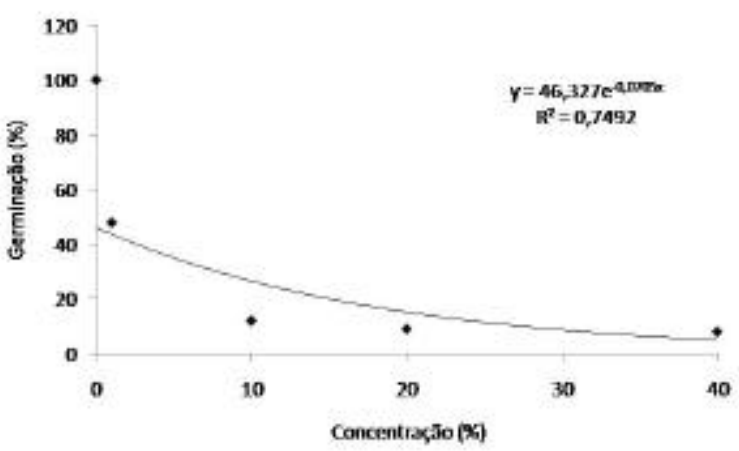

(a)

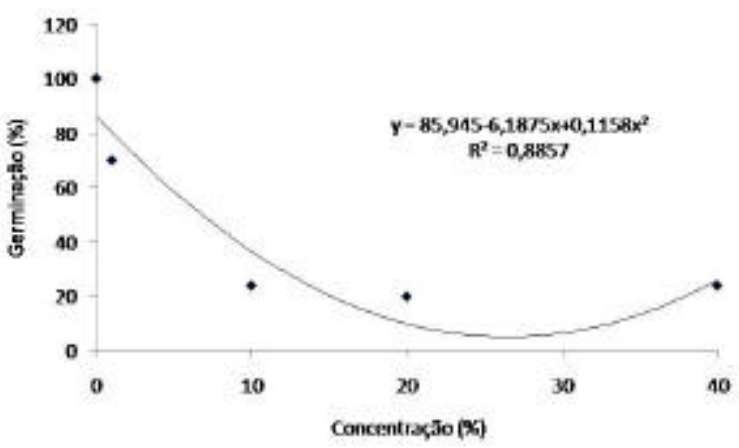

(c)

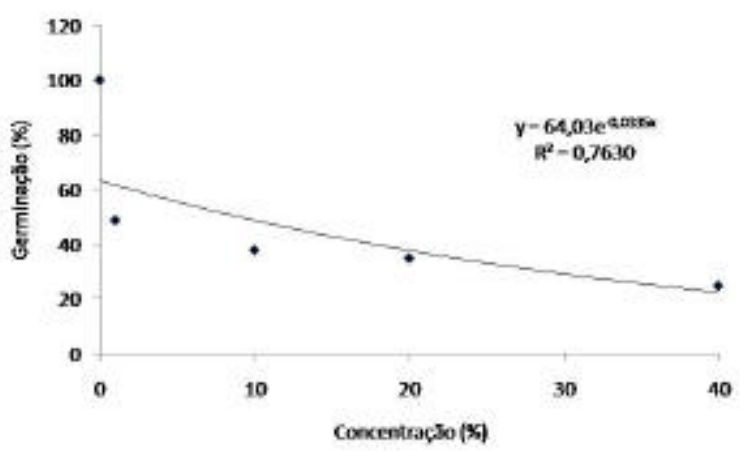

(b)

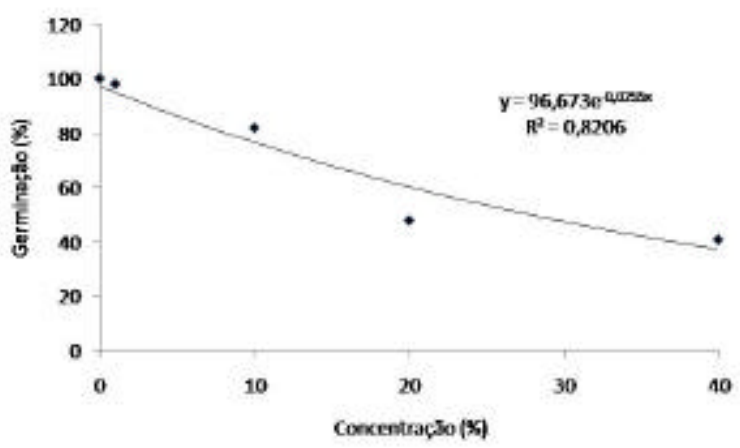

(d)

Fig. 3 - Germinação de Cladosporium fulvum sob diferentes concentrações de extratos brutos aquosos de (a) Achillea millefolium (b) Artemisia camphorata (c) Cymbopogon citratus e (d) Rosmarinus officinalis. Para a concentração $0 \%$ foi considerada uma germinação de $100 \%$.

Em relação à esporulação (Fig. 2), os dados para o EBA de A.millefolium ajustaram-sea uma reta, onde,com o aumento da concentração do EBA, houve redução de esporulação. Nas concentrações de $20 \%$ e $40 \%$ a esporulação foi reduzida 49,33\% e 65,63\%, respectivamente. Para os dados de EBA de A. camphorata e $R$. officinalis a curva ajustada foi a exponencial. Para oEBA de A. camphorata , a partir da concentração de $20 \%$, foi verificada redução de $85,72 \%$ na esporulação. Para o EBA de $R$. officinalis, na concentração de $40 \%$, ocorreu redução de esporulação de $93,49 \%$. Porém, o EBA de $C$. citratus incentivou a esporulação, apresentando resultados até superiores ao da testemunha.

Em relação à germinação dos esporos (Fig. 3), pela análise de regressão, a curva ajustada para a porcentagem de germinação foi exponencial, para os dados de EBA de A. millefolium, A. camphorata e R. officinalis. Para EBA deC. citratus a curva ajustava foi quadrática. Reduções significativas na porcentagem de germinação foram observadas a partir da concentração de $20 \%$ do EBA de A. millefolium, onde ocorreu redução de $88,68 \%$. Para os EBAs deA. camphoratae R. officinalis ocorreu redução de 83,23\% e 65,14\% na concentração de $40 \%$, respectivamente. Para o EBA deC. citratus, na concentração de $26,46 \%$, foi verificada uma redução $96,30 \%$, em relação à testemunha.
No presente trabalho foi verificado que o extrato de C. citratus inibiu de maneira parcial o crescimento micelial, e inibiu significativamente a germinação de esporos, embora tenha incrementado a esporulação. Vistoquea inibição da germinaçãodos esporoséfundamental no controle da doença, pois essa estrutura é o ponto de partida para a propagaçãoe sobrevivência dos fungos e necessária para a ocorrência de ciclos secundários, o extrato poderia influenciar de forma negativa no ciclodevida do patógenoa campo, reduzindoa ocorrência de epidemias. Isto ocorreu também para as outras plantas medicinais estudadas, havendo reduções parciais nocrescimento micelial eesporulação, porém reduções mais significativas na germinação de esporos.

A fungitoxicidade in vitro dos extratos brutos de $C$. citratus e Cymbopogon nardus sobre C. fulvum também foi verificada por BALDO et al. (2005), cujos extratos aquosos obtidos de folhas frescas foram incorporados em meio BDA, isoladamente ou em mistura, nas concentrações de1,5,10,15e20\%.Nestetrabalho, aatividadeantifúngica esteve presente em todos os parâmetros avaliados, sendoamédia deinibição de $77 \%$ para a massa micelial, $71 \%$ para esporulaçãoe $24 \%$ para germinaçãodeesporos, enquanto que para o fungicida azoxystrobin $(4,0 \mathrm{~g}$ i.a/L), utilizado como controle positivo, as inibições foram de $91 \%, 79 \%$ e $76 \%$, respectivamente. 
No caso da planta medicinalA.camphorata, asfolhas dessa planta possuem $0,8 \%$ de óleo essencial constituído por mais de $60 \%$ do composto terpenóide linalol (MARTINs etal.,1995). Extrato bruto eóleo essencial deA. camphorata têm mostrado resultados satisfatórios na inibição do crescimento micelial de alguns fungos (SchwAN-Estrada et al., 2000; FranZEner etal., 2003), bem como na indução de fitoalexinas em sorgo e soja (Stangarlin etal., 1999, SchWAN-Estrada et al., 2000). Em relação à planta medicinal $A$. millefolium, trabalhos realizados por SINGH et al. (1988) verificaram que a apigenina, um dos compostos fenólicos dessa planta e tambémde Echinopus echinatus, mostrou ser eficienteem inibir a germinação de conídios de Alternaria tenuissima em concentrações de 25 a $150 \mu \mathrm{g} / \mathrm{mL}$. Fiori et al.(2000), trabalhando com as plantas medicinais Eucalyptus citriodora, C. citratus, Ageratum conyzoides eA.millefolium, verificaram que todos os extratos foram eficientes em inibir o crescimento micelial, esporulação e germinação de esporos de Didymella bryoniae. Para a planta $R$. officinalis, trabalhos realizados por DAFERERA et al.(2003) indicaram que, in vitro, o óleo essencial não foi eficiente no controle de Botrytis cinerea, Fusarium solani var. coeruleum e Clavibacter michiganensis nas concentrações estudadas, pois somente a partir de $606 \mathrm{e} 668 \mu \mathrm{g} / \mathrm{mLfoi}$ que ocorreu redução de $50 \%$ do crescimento micelial de B. cinerea eFusarium, respectivamente. Eucaliptol $(31,5 \%)$ e borneol $(14,2 \%)$ foram os componentes encontrados em maior concentração no óleo. Já no trabalho de ROZWALKA (2003), oefeitodeextrato brutoeóleoessencial de várias plantas medicinais foi estudado no desenvolvimento dos fungos Glomerella cingulata e Colletotrichum gloeosporioides, verificou que o EBA de R. officinalis reduziu $67 \%$ e $47,49 \%$ o crescimento micelial desses fungos, respectivamente.

Tabela 1 - Número de lesões de Cladosporium fulvum em folhas de tomateiro tratadas (primeiro par de folhas) e não tratadas (segundo par de folhas) com extratos brutos aquosos de plantas medicinais.

\begin{tabular}{lcc}
\hline Tratamentos & \multicolumn{2}{c}{ No de lesões } \\
\cline { 2 - 3 } & $\begin{array}{c}\text { 10 par de } \\
\text { folhas }\end{array}$ & $\begin{array}{r}\text { 2o par de } \\
\text { folhas }\end{array}$ \\
\hline Testemunha & $9,83 \mathrm{a}$ & $3,17 \mathrm{a}$ \\
Achillea millefolium 10\% & $10,6 \mathrm{a}$ & $2,83 \mathrm{a}$ \\
20\% & $6,17 \mathrm{~b}$ & $2,66 \mathrm{a}$ \\
Artemisia camphorata 10\% & $7,33 \mathrm{a}$ & $0,00 \mathrm{~b}$ \\
20\% & $4,66 \mathrm{~b}$ & $0,00 \mathrm{~b}$ \\
Cymbopogon citratus 10 \% & $3,66 \mathrm{~b}$ & $3,00 \mathrm{a}$ \\
$20 \%$ & $8,17 \mathrm{a}$ & $3,17 \mathrm{a}$ \\
Rosmarinus officinalis 10\% & $6,50 \mathrm{~b}$ & $0,00 \mathrm{~b}$ \\
$20 \%$ & $5,00 \mathrm{~b}$ & $0,00 \mathrm{~b}$ \\
\hline
\end{tabular}

Médias nas colunas, seguidas de mesma letra, não diferem entre si pelo teste de Scott-Knott no nível de 5\% probabilidade.

\section{Severidade da doença em plântulas de tomate}

O número de lesões das folhas tratadas e inoculadas ( $1^{\circ}$ par de folhas) foi menor em relação à testemunha (Tabela 1), para os EBAs de A. millefolium e A.camphorata a $20 \%$ R.officinalis $10 \%$ e $20 \%$ eC.citratus $10 \%$. As diferenças observadas nos valores de severidade nas folhas podem ter ocorrido por atividade antimicrobiana direta dos extratos da plantas testadas, já que in vitro tais tratamentos foram capazes de inibir significativamente a porcentagem de germinação e o crescimento micelial. No entanto, não se pode descartar a possibilidade de ter ocorrido uma indução de resistência sistêmica, pois verificou-se uma redução ou até ausência de lesões em folhas acima das tratadas (2o par de folhas), principalmente para os EBAs de A.camphorata eR.officinalis ambos a 10 e $20 \%$. Resultados semelhantes foram encontrados porBALBIPeña et al. (2006b) que verificaram que o extrato do rizoma de cúrcuma (Curcuma longa) a 10\% promoveu uma possível indução de resistência sistêmica em plantas de tomateiro contra $A$. solani, pois houve menor aérea abaixo da curva de progresso da doença na folha tratada e também na não tratada. FRANZENER et al.(2003), utilizando o extrato bruto de A.camphorata para induzir resistência à Bipolaris sorokiniana em plantas de trigo, observaram uma redução no número e tamanho das lesões em plantas tratadas antes da inoculação do patógeno em relação às plantas não induzidas, corroborando com este trabalho acerca da atividade indutora desse extrato.

A atividadeindutora de resistência por extratos de A. millefolium e C. citratus também foi verificada por BECKER et al. (2002) contra mancha angular (Pseudomonas syringae pv. lachrymans) em pepino em cultivo orgânico. O extrato de C. citratus, em concentrações de $5 \%$ e $10 \%$, reduziu em média $36 \%$ a severidade, enquanto que para $A$. millefolium a redução média foi de $34 \%$, mesmos valores de proteção que o obtido pelo tratamento com calda bordalesa.

Para R. officinalis, BECKeret al. (2004), em trabalho com extrato dessa planta e também de $C$. longa e $C$. citratus, todos a 5 a $10 \%$, verificaram que a incidência de doenças de final de ciclo, como Septoria glycines Hemmi e Cercospora kikuchii (Matsu. \& Tomoyasu) Gardner, e oídio (Microsphaera diffusa Cke. \& Pk) em soja sob condições de campo, foi igual à do tratamento padrão com o fungicida pyraclostrobin + epoxiconazole, embora para $R$. officinalis a $5 \%$ e $C$. longa a $10 \%$, a produção (kg/ha) tenha sido $13 \%$ e $16 \%$ maior que a do fungicida. RöDER $(2003 ; 2006)$ observou que os extratos de R. officinalis e Ruta graveolens não foram capazes de controlar a podridão parda do pessegueiro na pós-colheita, entretanto o EBA de $R$. officinalis controlou a podridão causada por Rhizopus nigricans em morangos pós-colheitas. 


\section{Atividade da peroxidase}

No nível de 5\% de probabilidade pelo teste ScottKnott, não foi verificada diferença significativa entre os tratamentos, ou seja, não houve acréscimos nem decréscimos significativos da atividade da enzima peroxidase. Porém, no trabalho realizado por IURKIV et al. (2006), foi verificado um aumento na atividade da enzima peroxidase, quatro dias após a inoculação com A. solani em folhas de tomateiro, tratadas com extratos aquosos de rizoma de $C$. longa e soluções de curcumina, de forma local e sistêmica. RodRIGUEs etal. (2007) também verificaram aumento da atividade de peroxidase e redução na incidência de Sclerotinia sclerotiorum em alface, tratados com extratos de gengibre (Zingiber officinale). No presente trabalho, o intervalo de tempo entre o tratamento e a inoculação foi de três dias e, possivelmente, não foi o intervalo ideal para verificar a ativação da peroxidase, pois, segundo Pascholatr; Leite (1995), a proteção induzida em plantas é dependente do intervalo de tempo entre o tratamento inicial (tratamento indutor) e a subseqüente inoculação da planta com o patógeno (tratamento desafiador), o que indica que mudanças específicas no metabolismo da planta, envolvendo a síntese e/ou acúmulo de substâncias que são importantes neste fenômeno. Contudo, neste trabalho, ocorreram reduções significativas no número de lesões. Assim, é provável que outros mecanismos de defesa tenham sido ativados pelos EBAs, como respostas de defesa frente ao patógeno, tais como lignificação, papilas e também outras enzimas relacionadas à patogênese $(\alpha, 1-3$ glucanase, quitinases) levando a uma diminuição da severidade da cladosporiose no tomateiro.

\section{CONCLUSÃO}

Os extratos brutos das plantas medicinas testados possuem ação fungitóxica sobreCladosporium fulvum e, possivelmente, induzem a resistência sistêmica em tomateiro contra cladosporiose.

\section{REFERÊNCIAS}

ALVARENGA, M.A.R. Tomate: produção em campo, em casa-de-vegetação e em hidroponia. Lavras: Editora UFLA, 2004

AGÊNCIA NACIONAL DE VIGILÂNCIA SANITÁRIA. Brasil. Controlando agrotóxicos nos alimentos: o trabalho desenvolvido pela ANVISA, com as vigilâncias sanitárias dos Estados do AC, ES, GO, MG, MS, PA, PE, PR, RJ, RS, SC, SP, TO, a FIOCRUZ/INCQS e os laboratórios IAL/SP, IOM/FUNED, LACEN/PR e ITEPE/PE. Relatório de atividades 2001-2004. Brasília: ANVISA, 2005.
BALBI-PEÑA, M.I.; BECKER, A.; STANGARLIN, J.R.; FRANZENER, G.; LOPES M.C.; SCHWAN-ESTRADA, K.R.F. Controle de Alternaria solani em tomateiro por extratos de Curcuma longa e curcumina - I. Avaliação in vitro. Fitopatologia Brasileira, v.31, n.3, p.301-314, 2006 .

BALBI-PEÑA, M.I.; BECKER, A. STANGARLIN, J.R.; FRANZENER, G.; LOPES M.C.; SCHWAN-ESTRADA, K.R.F. Controle de Alternaria solani em tomateiro por extratos de Curcuma longa e curcumina-II. Avaliação in vivo. Fitopatologia Brasileira, v.31, n.4, p.401-404, 2006b.

BALDO, M.; SORNBERGER, A.; STANGARLIN, J.R.; GRISA, S.; ECKSTEIN, B.; GIESE, C.; SCHWANESTRADA, K.R.F. Potencial do extrato bruto de Cymbopogon citratus (capim-limão) e Cymbopogon nardus (citronela) no controle in vitro de Cladosporium fulvum do tomateiro. In: JORNADA CIENTÍFICA DA UNIOESTE, 3., 2005, Marechal Cândido Rondon, PR. Anais. Marechal Cândido Rondon: Unioeste, 2005.

BECKER, A.; FERNANDES, G.P.; CARRÉ, V.; ZANELLA, A.L.; FRANZENER, G.; KUHN, O.J.; PORTZ, R.L.; STANGARLIN, J.R.; SCHWAN-ESTRADA, K.R.F. Controle alternativo de doenças de pepino produzido em cultivo orgânico e protegido. Fitopatologia Brasileira. v.27, p.223, 2002. Suplemento. Trabalho apresentado no CONGRESSO BRASILEIRO DE FITOPATOLOGIA, 35., 2002, Recife. Resumos.

BECKER, A.; VIGO-SCHULTZ, S.C.; STANGARLIN, J.R.; BALBI-PEÑA, M.I.; KLAHOLD, C.A.; SCHWANESTRADA, K.R.F. Controle alternativo das doenças de final de ciclo e oídio na cultura da soja. Fitopatologia Brasileira. v.29, p.163, 2004. Suplemento. Trabalho apresentado no CONGRESSO BRASILEIRO DE FITOPATOLOGIA, 37., 2004, Gramado. Resumos.

BRADFORD, M.M. A rapid and sensitive method for the quantification of microgram quantities of protein utilizing the principle of protein-dye binding. Analytical Biochemistry, v.72, p.248-254, 1976.

CARNEIRO, S.M. de T.P.G. Efeito de extratos de folhas de nim sobre o oídio do tomateiro. Summa Phytopathologica, v.29 n.3, p.262-265, 2003.

CAVALCANTI, L.S.; DI PIERO, R.M.; CIA, P.; PASCHOLATI, S.F.; RESENDE, M.L.V.; ROMEIRO, R.S. (Ed.) Indução de resistência em plantas a patógenos e insetos. Piracicaba: FEALQ, 2005.

DAFERERA, D.J.; ZIOGASB, B.N.; POLISSIOU, M.G. The effectiveness of plant essential oils on the growth of Botrytis cinerea, Fusarium sp. and Clavibacter michiganensis subsp. michiganensis. Crop Protection, v.22, n.1, p.39-44, 2003.

FILGUEIRA, F.A.R. Solanáceas II. Tomate: a hortaliça cosmopolitana. In: Novo manual de olericultura, agrotecnologia moderna na produção e 
comercialização de hortaliças. Viçosa-MG: UFV, 2003. c.13, p.193-225.

FIORI, A.C.G.; SCHWAN-ESTRADA, K.R.F.; STANGARLIN, J.R.; VIDA, J.B.; SCAPIM, C.A.; CRUZ, M.E.S.; PASCHOLATI, S.F. Antifungal activity of leaf extracts and essencial oils of some medicinal plants against Didymella bryoniae. Journal of Phytopathology, v.148, p.483, 2000.

FRANZENER, G.; STANGARLIN, J.R.; SCHWANESTRADA, K.R.F.; CRUZ, M.E.S. Atividade antifúngica e indução de resistência em trigo a Bipolaris sorokiniana por Artemisia camphorata. Acta Scientiarum. Agronomy, v.25, n.2, p.503-507, 2003.

HAMMERSCHMIDT, T.; NUCKLES, E.M.; KUÆ, J. Association of enhanced peroxidase activity with induced systemic resistance of cucumber to Colletotrichum lagenarium. Physiological Plant Pathology, v.20, n.1, p.73-82, 1982.

IURKIV, L.; ECKSTEIN, B.; BALBI-PEÑA, M.I.; STANGARLIN, J.R.; SCHWAN- ESTRADA, K.R.F. Atividade de peroxidase em tomateiro tratado com Curcuma longa e inoculado com Alternaria solani. Summa Phytopathologica, v.32, supl., p.22, 2006. Suplemento. Trabalho apresentado no CONGRESSO PAULISTA DE FITOPATOLOGIA, 29., 2006, Botucatu.

KE-QIANG, C.; BRUGGEN, A.H.C. Inhibitory efficacy of several plant extracts and plant products on Phytophthora infestans. Journal of Agricultural University of Hebei, v.4, p.108-116, 2001

KESSMANN, H.; STAUB, T.; HOFMANN, C.; MAETZKE, T.; HERZOG, J.; WARD, E.; UKNES, S.; RYALS, J. Induction of systemic acquired disease resistance in plants by chemicals. Annual Review of Phytopathology, v.32, p.439-459, 1994.

LOPES, C. A.; SANTOS, J.R.M.; ÁVILA, A.C.; BEZERRA, I.C.; CHARCHAR, J.M.; DUVAL, A.M.Q. Doenças: Identificação e controle. In: SILVA, J.B.C. da; GIORDANO, L.B. (Org.). Tomate para processamento industrial. Brasília, DF: Embrapa Comunicação para Transferência de Tecnologia, 2000. v.único, p.88-111.

LYON, G.D.; REGLINSKI, T.; NEWTON, A.C. Novel disease control compounds: the potential to 'immunize' plants against infection. Plant Pathology, v.44, n.3, p.407-427, 1995.

MARTINS, E.R.; CASTRO, D.M. de; CASTELLANI, D.C.; DIAS, J.E. Plantas medicinais. Viçosa: UFV, 1995.

PASCHOLATI, S.F.; LEITE, B. Hospedeiro: Mecanismos de resistência. In. BERGAMIM FILHO, A.; KIMATI, H.; AMORIM, L. (Ed.). Manual de fitopatologia: Princípios e conceitos. São Paulo: Ed. Agronômica Ceres, 1995. v.1. p.417-454.
PRITHIVIRAJ, B.; SINGH, U.P.; MANICKAM, M.; SRIVASTAVA, J.S.; RAY, A.B. Antifungal activity of bergenin, a constituent of Flueggea microcarpa. Plant Pathology, v.46, n.2, p.224-228, 1997.

RAJA, J.; KURUCHEVE, V. Influence of plants extracts and buffalo urine on the growth and sclerotial germination of Macrophomina phaseolina. Indian Phytopathology, v.51, p.102-103, 1998.

RÖDER, C. Controle alternativo de podridões causadas por fungos na pós-colheita em pêssego e morango. 2003. 33p. Monografia (Curso de Agronomia) Universidade Estadual do Oeste do Paraná, Marechal Cândido Rondon, 2003.

RÖDER, C. Controle alternativo de podridões na cultura do morango com tratamentos em pré-colheita. 2006. 37p. Dissertação (Mestrado) - Universidade Estadual do Oeste do Paraná, Marechal Cândido Rondon, 2006

RODRIGUES, E.; SCHWAN-ESTRADA, K.R.F.; FIORITUTIDA, A.C.G.; STANGARLIN, J.R.; CRUZ, M.E.S. Fungitoxicidade, atividade elicitora de fitoalexinas e proteção de alface em sistema de cultivo orgânico contra Sclerotinia sclerotiorum pelo extrato de gengibre. Summa Phytopathologica, v.33, n.2, p.124-128, 2007.

ROZWALKA, L.C. Controle alternativo da antracnose em frutos de goiabeira, em laboratório. 2003. 45p. Dissertação (Mestrado) - Universidade Federal do Paraná, Curitiba, 2003.

SCHANEBERG, B.T.; KHAN, I.A. Comparison of extraction methods for marker compounds in the essential oil of lemon grass by GC., v.50, n.6, p.13451349, 2002.

SCHWAN-ESTRADA, K.R.F.; CRUZ, M.E.S.; STANGARLIN, J.R. Uso de extratos vegetais no controle de fungos fitopatogênicos. Revista Floresta, v.30, p.129-137, 2000

SCHWAN-ESTRADA, K.R.F.; STANGARLIN, J.R. Extratos e óleos essenciais de plantas medicinais na indução de resistência. In: CAVALCANTI, L.S.; DI PIERO, R.M.; CIA, P.; PASCHOLATI, S.F.; RESENDE, M.L.V.; ROMEIRO, R.S. (Ed.). Indução de resistência em plantas a patógenos e insetos. Piracicaba: FEALQ, 2005. p.125-138.

SINGH, R.; RAI, B. Antifungal potential of some higher plants against Fusarium udum causing wilt disease of Cajanus cajan. Microbios, v.102, n.403, p.165-173, 2000.

SINGH, U.P.; DANDEY, V.B.; SINGH, K.N.; SINGH, R.D.N. Antifungal activity of some new flavones and flavones glycosides of Echinops echinatus. Canadian Journal of Botany, v.66, p.1901-1903, 1988. 
STADNIK, M.J.; TALAMINI, V. Manejo ecológico de doenças de plantas. Florianópolis: UFSC, 2004. 293p.

STANGARLIN, J.R.; SCHWAN-ESTRADA, K.R.F.; CRUZ, M.E.S.; NOZAKI, M.H. Plantas medicinais e controle alternativo de fitopatógenos. Biotecnologia, Ciência \& Desenvolvimento, n.11, p.16-21, 1999.

Recebido em 14/8/07

Aceito em 25/11/08 